\title{
REVIEW
}

\section{Vitamin D deficiency in UK Asian families: activating a new concern}

\author{
N J Shaw, B R Pal
}

Arch Dis Child 2002;86:147-149

Vitamin D has steroid hormonal effects which can produce clinical symptoms and signs unrelated to calcium homoeostasis. Its deficiency has been implicated as a risk factor for diabetes, ischaemic heart disease, and tuberculosis in Asians. In this review, the incidence, aetiology, prevention, and treatment of symptomatic vitamin $D$ deficiency in childhood are considered. A renewed public health campaign is required in the UK to address the continuing problem of vitamin $D$ deficiency in Asian families.

See end of article for authors' affiliations

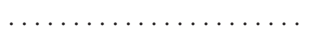

Correspondence to: Dr N J Shaw, Dept of Endocrinology,

Birmingham Children's Hospital, Steelhouse Lane, Birmingham $\mathrm{B} 46 \mathrm{NH}$, UK; nick.shaw@

bhamchildrens.wmids.nhs.uk

Accepted for publication 22 November 2001
$\mathrm{V}$ itamin D has wide ranging steroid hormonal effects which can produce clinical symptoms and signs unrelated to calcium homoeostasis. The explanation appears to be that the receptor for 1,25 vitamin $\mathrm{D}$ is present in most cells of the body, ${ }^{1}$ and there is widespread extrarenal expression of $1-\alpha$ hydroxylase, ${ }^{2}$ which catalyses synthesis of this hormone. 1,25 Vitamin $\mathrm{D}$ has a regulatory role in skeletal muscle, the immune system, and cell differentiation, including induction of proteins, such as nerve growth factor, in the central nervous system. Recently vitamin $\mathrm{D}$ deficiency has been implicated as a risk factor for diabetes, ischaemic heart disease, ${ }^{3}$ and tuberculosis in Asians. ${ }^{4}$

Prenatal famine and adult disease is now being increasingly recognised. Low maternal vitamin D may adversely affect the developing fetal brain. In addition to the previously known paediatric problems of hypocalcaemic fits, dental enamel hypoplasia, infantile rickets, and congenital cataracts in early life, vitamin D deficiency has been shown to affect postnatal head and linear growth. $^{5}$

In the UK, the Committee on Medical Aspects of Food Policy (COMA) recommends that all infants receive 7-8.5 $\mathrm{gg}$ (280-340 iu) of vitamin D daily either in a multivitamin preparation or in fortified infant formula milk. It recommends that all pregnant and lactating mothers should receive $10 \mu g$ (400 iu) of vitamin D daily, ${ }^{6}$ and advises that Asian children should be encouraged to take vitamin D supplements throughout the first five years of life.

\section{CHANGING INCIDENCE}

Deprivational vitamin D deficiency in Asians living in the UK, whose origins are from India, Pakistan, or Bangladesh, was first reported nearly 30 years ago. ${ }^{78}$ Various campaigns to improve life and social conditions, as well as recommendations advocating provision of free vitamin D sup- plements led to a decline in the prevalence of vitamin D deficiency in these ethnic groups. ${ }^{9}$

A questionnaire survey, commissioned by COMA in 1995, among West Midlands paediatricians, confirmed that the majority of the respondents reported seeing very few cases of rickets and when seen, were predominantly in AfroCaribbean toddlers rather than Asian infants.

However, we have seen a resurgence of vitamin D deficiency in Asian children in the past two to three years in Birmingham, experience mirrored by reports from elsewhere in the UK of vitamin D deficiency in infants (London), ${ }^{10}$ adults (Leicester), ${ }^{11}$ and pregnant women (Cardiff). ${ }^{12}$ In addition to rickets, infants have presented in the first six to nine months of life with symptomatic hypocalcaemia, particularly seizures; we have seen one case of life threatening cardiomyopathy.

Unlike other reports which have implicated prolonged and exclusive breast feeding, ${ }^{13}$ most of our infants have been both breast and formula fed and several have been receiving multivitamin supplements. These infants have all had evidence of severe vitamin D deficiency (25hydroxyvitamin $\mathrm{D}<8 \mathrm{ng} / \mathrm{ml}$ ) as have the majority of the mothers who have also been tested. Most of these infants have been born to mothers who were themselves born in the UK. It would appear that the previous recommendations regarding prevention have been largely forgotten and our initial enquiries indicate that most UK maternity units do not have a policy of providing vitamin D supplements to pregnant Asian women.

\section{AETIOLOGY}

The presentation of our cases and others ${ }^{14}$ highlights the importance of maternal vitamin D stores. Newborn infants depend on fetal stores of vitamin D obtained from their mother ${ }^{15}$; following delivery their vitamin D status is $60-70 \%$ of measured maternal vitamin D concentrations. ${ }^{16}$ No meta-analysis has been performed to assess the outcome of maternal vitamin D deficiency as the populations studied are either too diverse or contain too small numbers with the reports failing to provide summary statistics. Ongoing reports from throughout the world over a 20 year period show that a causal relation probably does exist between clinical symptoms and infant and maternal vitamin D deficiency.

A study of 25-hydroxyvitamin D concentrations in the resident non-pregnant adult population in the catchment area of one Birmingham hospital, showed that in winter, $85 \%$ of Asians, compared to $3.3 \%$ of non-Asians, had vitamin D concentrations less than $8 \mathrm{ng} / \mathrm{ml}$. Furthermore during summer, $38 \%$ of the Asians still had 
vitamin D concentrations less than $10 \mathrm{ng} / \mathrm{ml}$. Previous reports from the UK and other European countries have also found differences between Asian and non-Asian groups. Shaunak and colleagues ${ }^{17}$ found $22 \%$ of healthy adult Asian couples (both sexes) had vitamin D deficiency (25-hydroxyvitamin D $<10 \mathrm{ng} / \mathrm{ml}$ ) with normal concentrations in white controls. A recent survey in Cardiff of vitamin D concentrations in pregnant women showed that $54 \%$ of Asian women had biochemical vitamin D deficiency $(<8 \mathrm{ng} / \mathrm{ml}) .{ }^{18}$ A survey undertaken in Norway ${ }^{19}$ showed that $83 \%$ of pregnant Pakistani women were vitamin D deficient.

Previous studies have attributed vitamin D deficiency in Asian women to cultural and dietary habits and their infrequent use of supplementation. The main source of vitamin $\mathrm{D}$ is from ultraviolet irradiation of the skin; there is no radiation of the appropriate wavelength (290-310 $\mathrm{nm})$ in Britain from the end of October to the end of March. For the remaining months of the year, $60 \%$ of the effective ultraviolet radiation occurs between 1100 and 1500. Although lack of sunlight exposure is important, this is probably not the only factor, as the vitamin D study undertaken in Birmingham also showed a high prevalence in men. Furthermore, a recent study from Delhi ${ }^{20}$ has found that excessive numbers of healthy Asian subjects have low 25-hydroxyvitamin D concentrations while residing in abundant sunlight.

In order to answer this dilemma, work undertaken in the $\mathrm{USA}^{21}$ has shown that altered vitamin D metabolism caused by notably increased 25-OHD,24 hydroxylase activity may be responsible for low 25-hydroxyvitamin $\mathrm{D}_{3}$ concentrations in Asians. Thus, it appears they may have a genetic predisposition to vitamin D deficiency. This suboptimal vitamin D status facilitates the occurrence of symptomatic vitamin D deficiency when there are increased requirements, as in early childhood, adolescence, pregnancy, and lactation.

Normally the calcium demands of pregnancy and lactation occur through a two- to threefold upregulation of intestinal calcium absorption in late pregnancy and during lactation. ${ }^{22}$ This is mediated by a similar twofold pregnancy induced rise in 1,25-dihydroxyvitamin $\mathrm{D}_{3}$ during the second and third trimesters with a concomitant reciprocal $50 \%$ fall in parathormone. ${ }^{23}$ We postulate that in vitamin $\mathrm{D}$ deficient Asian women during pregnancy, the mechanism of calcium upregulation by a rise in 1,25-dihydroxyvitamin $\mathrm{D}_{3}$ is lacking and hence vitamin $\mathrm{D}$ resources are restricted to the fetus.

\section{PREVENTION}

It is apparent that relying on vitamin $\mathrm{D}$ supplements given to infants or the amounts present in formula feeds is inadequate to overcome the impact of maternal vitamin D deficiency. It is important to ensure that fetal stores are optimised by supplementation of at risk mothers. A 400 iu daily dose of vitamin D should theoretically result in normal concentrations of 25-hydroxyvitamin $\mathrm{D}_{3}$ and 1,25-dihydroxyvitamin $\mathrm{D}_{3}$. However, a recent study from Denmark undertaken in veiled Moslem women indicates that, in the absence of sunlight exposure, a dietary intake of 600 iu vitamin D per day is insufficient to maintain adequate 25 -hydroxyvitamin D concentrations; the authors suggested that 1000 iu per day would be more effective. ${ }^{24}$ Screening pregnant Asian women for vitamin D status and supplementing as necessary has been suggested. ${ }^{18}$ However, this can only be advocated after clarifying a nationally agreed "deficient range" for vitamin $\mathrm{D}$, the optimal time to screen in pregnancy, and the most appropriate vitamin $\mathrm{D}$ dose to achieve compliance, efficacy, and minimal risk.

It would be simpler to supplement all pregnant Asian women with vitamin D. There are, however, problems in compliance with vitamin D supplementation, particularly when intended to be taken daily. A recent health programme in Norway, ${ }^{25}$ consisting of free samples of $10 \mu g$ (400 iu) vitamin
D daily combined with information, failed to reduce vitamin D deficiency to acceptably low concentrations in Pakistani mothers. An alternative is to give $25 \mu \mathrm{g}$ ( $1000 \mathrm{iu}$ ) daily during the third trimester, which has been shown to produce normal 25-hydroxyvitamin D concentrations in mothers and infants at term. ${ }^{26}$ Another proposal is a single high dose of vitamin D of 100000-200000 iu given during the sixth or seventh month of pregnancy, which appears sufficient to cover both maternal and fetal needs. ${ }^{27}$ Adequately controlled antenatal vitamin D supplementation trials are $\mathrm{few},{ }^{28}$ although Brooke et al in London ${ }^{26}$ and Mallet et al in northwest France, ${ }^{29}$ who performed case matched cohort studies, identified that antenatal maternal vitamin D concentrations are correlated with infant status.

As regards infants, it is clear that national recommendations about vitamin $\mathrm{D}$ supplements are not being followed. We believe all Asian infants should be given 400 iu vitamin D daily whether breast or formula fed. Alternatively, if poor daily compliance is a problem, an annual dose ( $4 \mathrm{mg}, 150000 \mathrm{iu})$ at the beginning of autumn, appears to provide protection against vitamin D deficiency without vitamin D overload. ${ }^{30}$

\section{TREATMENT OF SYMPTOMATIC VITAMIN D DEFICIENCY IN CHILDHOOD}

The most effective and physiological treatment for an infant with symptomatic hypocalcaemia, or rickets caused by vitamin $\mathrm{D}$ deficiency, is either ergocalciferol (vitamin $\mathrm{D}_{2}$ ) or cholecalciferol (vitamin $\mathrm{D}_{3}$ ). This is the fastest means to replenish the depleted 25 -hydroxyvitamin D concentrations, improve intestinal calcium absorption, and suppress the effect of secondary hyperparathyroidism. Alfacalcidol or calcitriol are not appropriate treatments, and children treated with these preparations initially are often resistant to their effect. In the UK, preparations of ergocalciferol or cholecalciferol are not readily available and a liquid preparation suitable for infants is not listed in the British National Formulary (BNF). A calciferol solution containing 3000 units per $\mathrm{ml}$ is available from Martindale Pharmaceuticals (Bampton Road, Harold Hill, Romford, Essex RM3 8UG) and is listed in Medicines for Children. ${ }^{31}$ A dose of 3000 units daily for infants less than 6 months and 6000 units daily for those older than 6 months for six weeks to four months is usually adequate to replenish depleted vitamin D stores, correct biochemical abnormalities, and heal rickets. Oral calcium supplements are also usually required initially if the child is hypocalcaemic and/or dietary intake is poor. It is not necessary to continue treatment until any leg deformity resolves, which may take up to two years. For the occasional adolescent presenting with symptomatic hypocalcaemia, a tablet preparation containing 10000 units of cholecalciferol is listed in the BNF and is the most appropriate for this age group. In addition to monitoring calcium, phosphate, and alkaline phosphatase while on treatment, serum parathormone is useful as it should normalise when the vitamin D deficiency has resolved.

\section{RECOMMENDATIONS}

It is our opinion that a renewed public health campaign is required in the UK to address the continuing problem of vitamin D deficiency in Asian families. Local circumstances will probably dictate what are the most cost effective measures. Our current recommendations would be:

- The definition of 25-hydroxyvitamin D deficiency should be standardised in the UK to $<8 \mathrm{ng} / \mathrm{ml}$ during winter and $<10$ $\mathrm{ng} / \mathrm{ml}$ during summer, so that reports of prevalence can be compared.

- All pregnant Asian women should receive vitamin D supplements-either 400 iu daily from the booking clinic appointment or 1000 units daily during the third trimester. Alternatively a single dose of ergocalciferol (100 000- 
$200000 \mathrm{iu}$ ) during the sixth or seventh month may be preferred to achieve best efficacy and compliance.

- All Asian infants, whether formula or breast fed, should receive 400 iu vitamin D daily. Alternatively an annual regimen may provide a higher compliance rate.

- Awareness of the risks of vitamin D deficiency should be increased in all Asian families.

\section{ACKNOWLEDGEMENTS}

We acknowledge Dr A Aukett for permission to quote the COMA survey, and C James, City Hospital, for access to the adult vitamin D study

\section{Authors' affiliations}

N J Shaw, Dept of Endocrinology, Birmingham Children's Hospital, UK B R Pal, Dept of Neonatal Medicine, Walsgrave Hospital, Coventry, UK

\section{REFERENCES}

1 Sandgren ME, Bronnegard M, DeLuca HF. Tissue distribution of the 1,25-dihydroxyvitamin $D_{3}$ receptor in the male rat. Biochem Biophys Res Commun 1991;181:611-16.

2 Zehnder D, Bland R, Williams MC, et al. Extrarenal expression of 25-hydroxyvitamin d(3)-1 alpha-hydroxylase. J Clin Endocrinol Metab 2001;86:888-94.

3 Boucher BJ. Inadequate vitamin D status: does it contribute to the disorders comprising syndrome ' $X$ '? Br J Nutr 1998;79:315-27.

4 Wilkinson RJ, Llewelyn $M$, Toossi $Z$, et al. Influence of vitamin $D$ deficiency and vitamin $D$ receptor polymorphisms on tuberculosis among Gujarati Asians in west London: a case control study. Lancet 2000;355:618-21.

5 Brunvand L, Quigstad E, Urdal P, Haug E. Vitamin D deficiency and fetal growth. Early Hum Dev 1996;45:27-33.

6 Department of Health. Dietary reference values for food energy and nutrients for the United Kingdom. Report on health and social subjects 41. London: HMSO, 1991.

7 Ford JA, Colhoun EM, Mclntosh WB, Dunnigan MG. Rickets and osteomalacia in the Glasgow Pakistani community, 1961-1971. BM 1972;2:677-80

8 Ford JA, Mclntosh WV, Butterfield R, et al. Clinical and subclinical vitamin D deficiency in Bradford children. Arch Dis Child 1976;51:939-43.

9 Dunnigan MG, Glekin BM, Henderson JB, et al. Prevention of rickets in Asian children: assessment of the Glasgow campaign. BM 1985;291:239-42.

10 Lawson $M$, Thomas M. Vitamin D concentrations in Asian children aged 2 years living in England: population survey. BMU 1999;318:28.

11 Iqbal SJ, Kaddam I, Wassif W, et al. Continuing clinically severe vitamin D deficiency in Asians in the UK (Leicester). Postgrad Med J 1994;70:708-14.
12 Alfaham M, Woodhead S, Pask G, Davies D. Vitamin D deficiency: a concern in pregnant Asian women. Br J Nutr 1995;73:881-7.

13 Mughal MZ, Salama H, Greenaway T, et al. Florid rickets associated with prolonged breast feeding without vitamin $D$ supplementation. BM 1999:318:39-40.6

14 Blond MH, Gold F, Pierre F, et al. Nutritional fetal rickets. A case report. J Gynecol Obstet Biol Reprod 1997;26:834-6.

15 Clements MR, Fraser DR. Vitamin D supply to the rat fetus and neonate. J Clin Invest 1988;81:1768-73.

16 Waiters B, Godel JC, Basu TK. Perinatal vitamin D and calcium status of northern Canadian mothers and their newborn infants. J Am Coll Nutr 1999;18:122-6.

17 Shaunak S, Colston K, Ang L, et al. Vitamin D deficiency in adult British Hindu Asians: a family disorder. BMU 1985;291:1166-8.

18 Datta S, Dunstan F, Woodhead S, et al. Vitamin D deficiency is very common in pregnant non-European ethnic minority women. Arch Dis Child 1999;80(suppl 1):A66.

19 Henriksen C, Brunvard L, Stoltenberg C, et al. Diet and vitamin D status among pregnant Pakistani women in Oslo. Eur J Clin Nutr 1995:49:211-18

20 Goswami R, Gupta N, Goqwami D, et al. Prevalence and significance of low 25 -hydroxyvitamin $\mathrm{D}$ concentrations in healthy subjects in Delhi. Am J Clin Nutr 2000;72:472-5.

21 Awumey EM, Mitra DA, Hollis BW, et al. Vitamin D metabolism is altered in Asian Indians in the southern United States: a clinical research center study. J Clin Endocrinol Metab 1998;83:169-73.

22 Zhu Y, Goff JP, Reinhardt TA, Horst RL Pregnancy and lactation increase vitamin D-dependent intestinal membrane calcium adenosine triphosphatase and calcium binding protein messenger ribonucleic acid expression. Endocrinology 1998;139:3520-4.

23 Seely EW, Brown EM, DeMaggio DM, et al. A prospective study of calciotropic hormones in pregnancy and post partum: reciprocal changes in serum intact parathyroid hormone and 1,25-dihydroxyvitamin D. Am J Obstet Gynecol 1997; 176:214-17.

24 Glerup H, Mikkelsen K, Poulsen L, et al. Commonly recommended daily intake of vitamin $D$ is not sufficient if sunlight exposure is limited. J Intern Med 2000;247:260-8

25 Brunvand L, Henriken C, Haug E. Vitamin D deficiency among pregnant women from Pakistan. How best to prevent it? Tidsskr Nor Laegeforen 1996:116:1585-7.

26 Brooke OG, Brown IR, Bone CD, et al. Vitamin D supplements in pregnant Asian women: effects on calcium status and fetal growth. BM 1980;280:751-4.

27 Hellouin de Menibus C, Mallet E, Henocq A, et al. Neonatal hypocalcemia. Results of vitamin D supplement in the mother. Study on 13,377 newborn infants. Bull Acad Natl Med 1990;174:1051-60.

28 Mahomed K, Gulmezoglu AM. Vitamin D supplementation in pregnancy. Cochrane Database Systematic Review 2000;2:CD000228.

29 Mallet E, Gugi B, Brunelle P, et al. Vitamin D supplemenatation in pregnancy: a controlled trial of two methods. Obstet Gynecol 1986;68:300-4

30 Oliveri B, Cassinelli H, Mautalen C, Ayala M. Vitamin D prophylaxis in children with a single dose of 150,000 IU of vitamin D. Eur J Clin Nutr 1996;50:807-10.

31 Royal College of Paediatrics and Child Health. Medicines for Children. London: RCPCH Publications Ltd, 1999:109. 